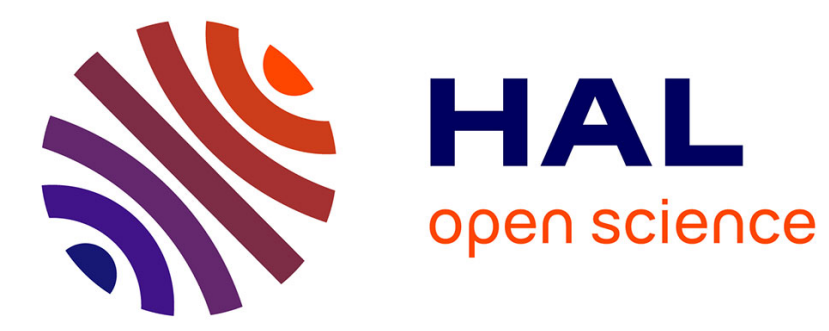

\title{
Silicon atomic layer growth using flash heating in CVD
}

\author{
M. Sakuraba, J. Murota, S. Ono
}

\section{To cite this version:}

M. Sakuraba, J. Murota, S. Ono. Silicon atomic layer growth using flash heating in CVD. Journal de Physique IV Proceedings, 1993, 03 (C3), pp.C3-449-C3-456. 10.1051/jp4:1993362 . jpa-00251419

\section{HAL Id: jpa-00251419 https://hal.science/jpa-00251419}

Submitted on 1 Jan 1993

HAL is a multi-disciplinary open access archive for the deposit and dissemination of scientific research documents, whether they are published or not. The documents may come from teaching and research institutions in France or abroad, or from public or private research centers.
L'archive ouverte pluridisciplinaire HAL, est destinée au dépôt et à la diffusion de documents scientifiques de niveau recherche, publiés ou non, émanant des établissements d'enseignement et de recherche français ou étrangers, des laboratoires publics ou privés. 


\title{
Silicon atomic layer growth using flash heating in CVD
}

\author{
M. SAKURABA, J. MUROTA and S. ONO
}

Laboratory for Microelectronics, Research Institute of Electrical Communication, Tohoku University, 2-1-1 Katahira, Aoba-ku, Sendai 980, Japan

\begin{abstract}
Si atomic layer growth on $\mathrm{Si}$ was investigated by heating the surface with a Xe flash lamp in an ultraclean low-pressure environment of $\mathrm{SiH}_{4}$ or $\mathrm{Si}_{2} \mathrm{H}_{6}$ gas. In the case of $\mathrm{SiH}_{4}$, about 0.4 atomic layer deposition per single flash light shot was observed on $\mathrm{Si}(100)$ at a substrate temperature of $385^{\circ} \mathrm{C}$ and at a $\mathrm{SiH}_{4}$ partial pressure of 500Pa. The adsorption process of $\mathrm{SiH}_{4}$ can be explained quantitatively by Langmuir-type adsorption model, assuming that the total adsorption site density is equal to the surface atom density. It was found that the amount of adsorbed $\mathrm{SiH}_{4}$ molecules is determined by the balance between adsorption and desorption of $\mathrm{SiH}_{4}$. In the case of $\mathrm{Si}_{2} \mathrm{H}_{6}$, sub-monolayer growth of $\mathrm{Si}$ was observed at a substrate temperature of $320^{\circ} \mathrm{C}$ and under $\mathrm{Si}_{2} \mathrm{H}_{6}$ partial pressure of $300 \mathrm{~Pa}$. From the RHEED observation, epitaxial growth of Si films on $\mathrm{Si}(100)$ was confirmed to be realized at low temperatures such as $385^{\circ} \mathrm{C}$ and $320^{\circ} \mathrm{C}$ by using $\mathrm{SiH}_{4}$ and $\mathrm{Si}_{2} \mathrm{H}_{6}$, respectively, and the surface flatness of the deposited films was as good as that of the initial surface.
\end{abstract}

\section{1.-Introduction.}

Atomic layer epitaxy of $\mathrm{Si}$ and $\mathrm{Ge}$ in chemical vapour deposition(CVD) is attractive for the progress of future semiconductor devices, e.g. ultrasmall devices and hetero devices. In conventional CVD, surface adsorption and reaction of reactant gases proceed simultaneously. In order to achieve atomic layer control, it is important to separate the adsorption process and the reaction process. So far, in atomic layer epitaxy[1-4], the self-limiting process of gas adsorption has been employed using metal organic or chloride gases which form a strong chemical bond between surface atoms and adsorbed molecules. In order to prevent any contamination of deposited films, simple hydride gases such as $\mathrm{GeH}_{4}, \mathrm{SiH}_{4}$ or $\mathrm{Si}_{2} \mathrm{H}_{6}$ without carbon or halogen should be used as the reactant gas. The studies of $\mathrm{SiH}_{4}$ and $\mathrm{Si}_{2} \mathrm{H}_{6}$ adsorption process on $\mathrm{Si}$ surfaces in an ultrahigh vacuum have been reported[5]. However, atomic layer growth of $\mathrm{Si}$ using these hydride gases had not been reported so far. In the previous work, the atomic layer epitaxy of $\mathrm{Ge}$ using $\mathrm{GeH}_{4}$ gas has been achieved by heating the surface with a Xe flash lamp in an ultraclean low-pressure environment[6-8]. In the present work, Si atomic 


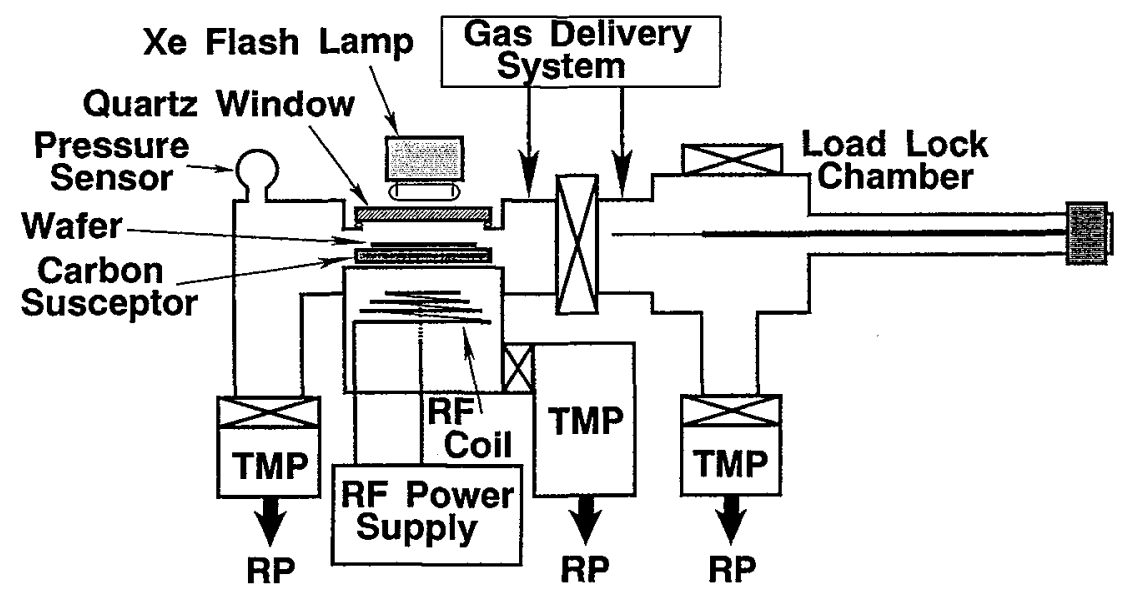

Fig.1.-Schematic diagram of an ultraclean RF-heated cold-wall lowpressure CVD system with Xe flash lamp.

layer growth process on $\mathrm{Si}$ substrate was investigated by the flash heating method, and sub-monolayer epitaxial growth of $\mathrm{Si}$ per shot of flash light has been achieved using $\mathrm{SiH}_{4}$ and $\mathrm{Si}_{2} \mathrm{H}_{6}$ gases at $385^{\circ} \mathrm{C}$ and $320^{\circ} \mathrm{C}$, respectively. Furthermore, the $\mathrm{SiH}_{4}$ and $\mathrm{Si}_{2} \mathrm{H}_{6}$ adsorption mechanisms are discussed.

\section{2.-Experimental.}

$\mathrm{Si}$ deposition on $\mathrm{Si}$ was carried out using $\mathrm{SiH}_{4}$ or $\mathrm{Si}_{2} \mathrm{H}_{6}$ in an ultraclean $\mathrm{RF}$-heated cold-wall low-pressure CVD system as schematically shown in Figure 1 . The system was made ultrahigh vacuum compatible with gate valves, turbo molecular pumps and a load-lock chamber. Moisture levels of used $\mathrm{Ar}, \mathrm{SiH}_{4}$ and $\mathrm{Si}_{2} \mathrm{H}_{6}$ gases at the reactor

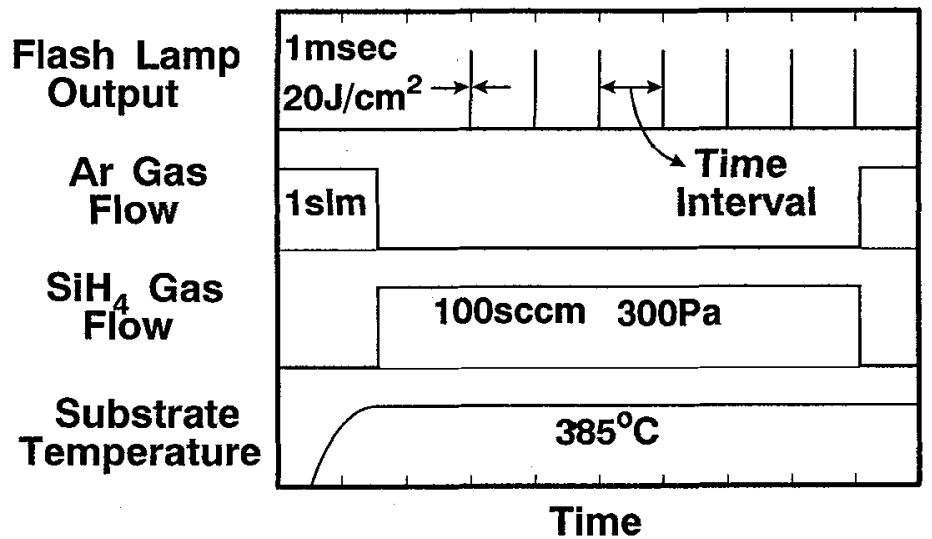

Fig.2.-Typical deposition sequence after setting the samples on the susceptor in the reactor. 
inlet were $10 \mathrm{ppb}$ or lower. The substrates are set into the load-lock chamber and transported into the reactor under evacuation with a simultaneous ultraclean Ar gas flow to avoid contamination from the exhaust line[9]. A typical deposition time sequence after the substrates were placed on the susceptor is shown in Figure 2. While heating the substrates, $\mathrm{SiH}_{4}$ or $\mathrm{Si}_{2} \mathrm{H}_{6}$ gas is introduced into the reactor and then $\mathrm{SiH}_{4}$ or $\mathrm{Si}_{2} \mathrm{H}_{6}$ molecules adsorbed at the surface are decomposed by $\mathrm{Xe}$ flash lamp light shots (duration about $1 \mathrm{msec}, 20 \mathrm{~J} / \mathrm{cm}^{2}$ ). The flash light shots were incident perpendicularly upon substrates. The shot to shot interval was of a few tens of seconds. The substrate surface temperature prior the light incidence was measured by an optical pyrometer. The substrates used were p-type Si wafers of $2-20 \Omega-\mathrm{cm}$ with a mirror polished (100) surface. Before loading the substrates into the load-lock chamber, they were cleaned in several cycles in a $4: 1$ solution of $\mathrm{H}_{2} \mathrm{SO}_{4}$ and $\mathrm{H}_{2} \mathrm{O}_{2}$, high purity DI water, $2 \% \mathrm{HF}$ with a final rinse in DI water. The deposited thickness, after repetition of hundreds cycles of flash shots, was measured by Tencor Alpha Step. The structure of the film surface was evaluated by reflection high-energy electron diffraction (RHEED).

\section{3.-Results and discussion.}

Figure 3 shows the substrate temperature dependence of the deposited film thickness per shot of flash light. In the case of $\mathrm{SiH}_{4}$ gas, the deposited thickness per shot of flash light is found to be about $0.4 \AA$, which is independent of the substrate temperature in the substrate temperature range of $385-395^{\circ} \mathrm{C}$, on $\mathrm{Si}(100)$ at a $\mathrm{SiH}_{4}$ partial pressure of $300 \mathrm{~Pa}$ and at a shot to shot time interval of $40 \mathrm{sec}$. It should be noted that the increase in the deposited thickness per shot of flash light observed at substrate temperatures above

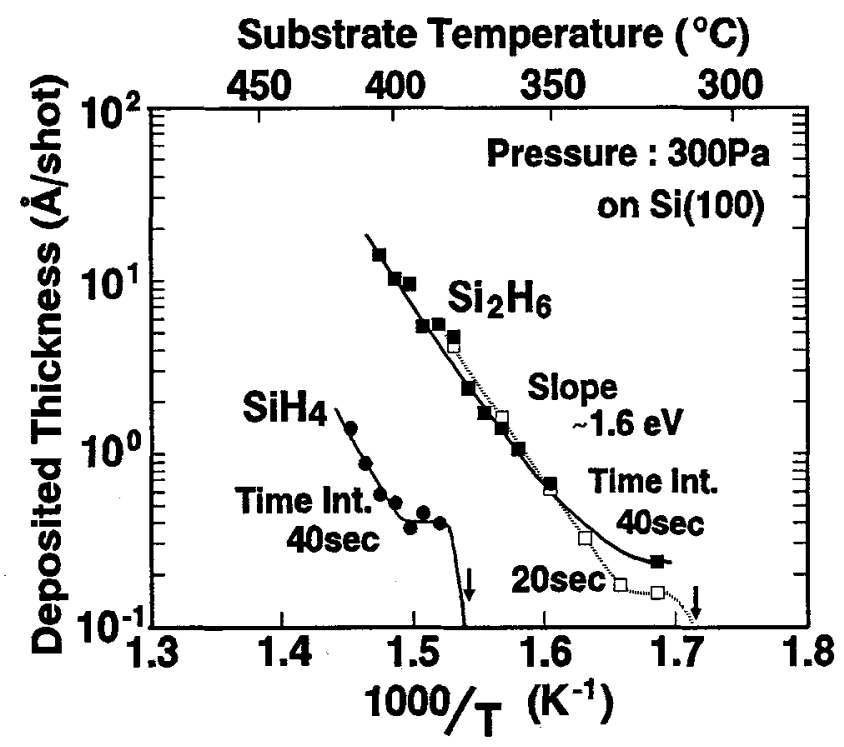

Fig.3.-Substrate temperature dependence of the deposited $\mathrm{Si}$ film thickness per flash light shot on $\mathrm{Si}(100)$ surface. The $\mathrm{SiH}_{4}$ or $\mathrm{Si}_{2} \mathrm{H}_{6}$ partial pressure is $300 \mathrm{~Pa}$. Arrows show no deposition. 


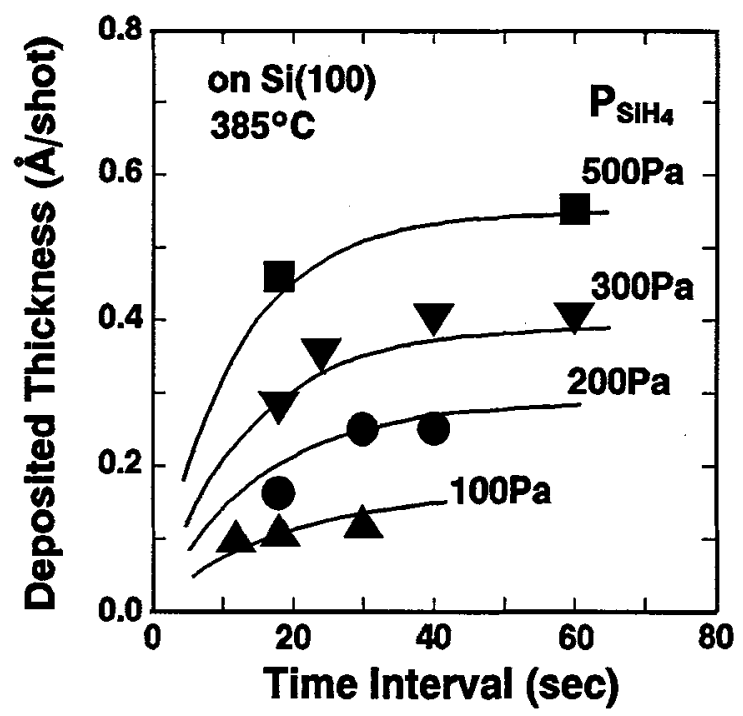

Fig.4.-Shot to shot time interval dependence of deposited Si film thickness per flash light shot at the $\mathrm{SiH}_{4}$ partial pressures of $100-500 \mathrm{~Pa}$ on $\operatorname{Si}(100)$ substrate at a substrate temperature of $385^{\circ} \mathrm{C}$.

$400^{\circ} \mathrm{C}$ may be explained by continuous $\mathrm{SiH}_{4}$ decomposition during the interval between flash light shots. Figure 4 shows the shot to shot time interval dependence of the deposited film thickness per shot of flash light on $\mathrm{Si}(100)$. It is found that the deposited thickness initially increases and saturates with the time interval. This saturation means that continuous $\mathrm{SiH}_{4}$ decomposition during the flash light shot interval scarcely occurs. As shown in the figure, the thicknesses on $\mathrm{Si}(100)$ in the saturation region are about $0.12 \AA, 0.40 \AA$ and $0.55 \AA$ for $100 \mathrm{~Pa}, 300 \mathrm{~Pa}$ and $500 \mathrm{~Pa}$, respectively. This means that the saturated amount of adsorbed $\mathrm{SiH}_{4}$ molecules is determined by the balance between adsorption and desorption of $\mathrm{SiH}_{4}$ on the surface.

Assuming that one $\mathrm{SiH}_{4}$ molecule is adsorbed at a single adsorption site, the total adsorption site density on the surface $n_{0}$ can be described by

$$
\mathbf{n}_{0}=Q_{S_{i H 4}}+Q_{S}
$$

where $Q_{\text {SiH4 }}$ and $Q_{S}$ are the densities of the surface site at which $\mathrm{SiH}_{4}$ is adsorbed, and not adsorbed, respectively. It is also assumed that the adsorption of atomic hydrogen or other species is negligibly small compared with $\mathrm{Q}_{\mathrm{SiH} 4}$ or has no influence on the $\mathrm{SiH}_{4}$ adsorption. Assuming that the $\mathrm{SiH}_{4}$ adsorption process is based on the Langmuir-type adsorption, the surface coverage velocity of $\mathrm{SiH}_{4}$ is given by

$$
\begin{aligned}
\frac{d Q_{\mathrm{SiH} 4}}{d t} & =k_{1} P_{S i H 4} Q_{S}-k_{-1} Q_{S i H 4} \\
& =k_{1} P_{S_{i H} 4} n_{0}-\left(k_{1} P_{S i H 4}+k_{-1}\right) Q_{S i H 4},
\end{aligned}
$$

where $\mathrm{k}_{1}$ and $\mathrm{k}_{-1}$ are the rate constants of $\mathrm{SiH}_{4}$ adsorption and desorption, respectively, $\mathrm{P}_{\mathrm{SiH} 4}$ is the $\mathrm{SiH}_{4}$ partial pressure. Assuming that $\mathrm{Q}_{\mathrm{SiH} 4}=0$ at $\mathrm{t}=0$, the integration of the equation (2) gives 


$$
Q_{S i H 4}=\frac{k_{1} P_{S i H 4} n_{0}}{k_{1} P_{S i H 4}+k_{-1}}\left[1-\exp \left\{-\left(k_{1} P_{S i H 4}+k_{-1}\right) \tau\right\}\right],
$$

where $\tau$ is the shot to shot time interval. The deposited thickness per shot of flash light can be expressed by a product of atomic layer thickness $\left(\mathrm{d}_{\mathrm{AL}}\right)$ and surface coverage $\left(\mathrm{Q}_{\mathrm{SiH} 4} / \mathrm{N}, \mathrm{N}\right.$ is the surface atom density) as the following Langmuir-type equation.

$$
\begin{aligned}
& \text { (Deposited thickness / shot) }=d_{\mathrm{AL}} \frac{\mathrm{Q}_{\mathrm{SiH} 4}}{\mathrm{~N}} \\
& \qquad=\mathbf{d}_{\mathrm{AL}} \frac{\mathbf{n}_{0}}{\mathrm{~N}} \frac{\mathbf{k}_{1} \mathbf{P}_{\mathrm{SiH} 4}}{\mathbf{k}_{1} \mathbf{P}_{\mathrm{SiH} 4}+\mathbf{k}_{-1}}\left[1-\exp \left\{-\left(\mathbf{k}_{1} \mathbf{P}_{\mathrm{SiH} 4}+\mathbf{k}_{-1}\right) \tau\right\}\right] .
\end{aligned}
$$

For $\tau \rightarrow \infty$,

$$
\frac{d_{A L}}{(\text { Deposited thickness / shot ) }}=\frac{N}{n_{0}} \frac{k_{-1}}{k_{1}} \frac{1}{P_{S i H 4}}+\frac{N}{n_{0}}
$$

Figure 5 shows the $\left(\mathrm{P}_{\mathrm{SiH} 4}\right)^{-1}$ dependence of the inverse of deposited thickness per shot of flash light in the saturation regions in Figure 4. It is found that data in Figure 5 can be described by the equation (5) with $N / n_{0}=1$. Therefore, it is considered that the total adsorption site density $\mathrm{n}_{0}$ is equal to the surface atom density $\mathrm{N}$ and one $\mathrm{SiH}_{4}$ molecule can occupy only one adsorption site. Solid curves shown in Figure 4 are obtained from

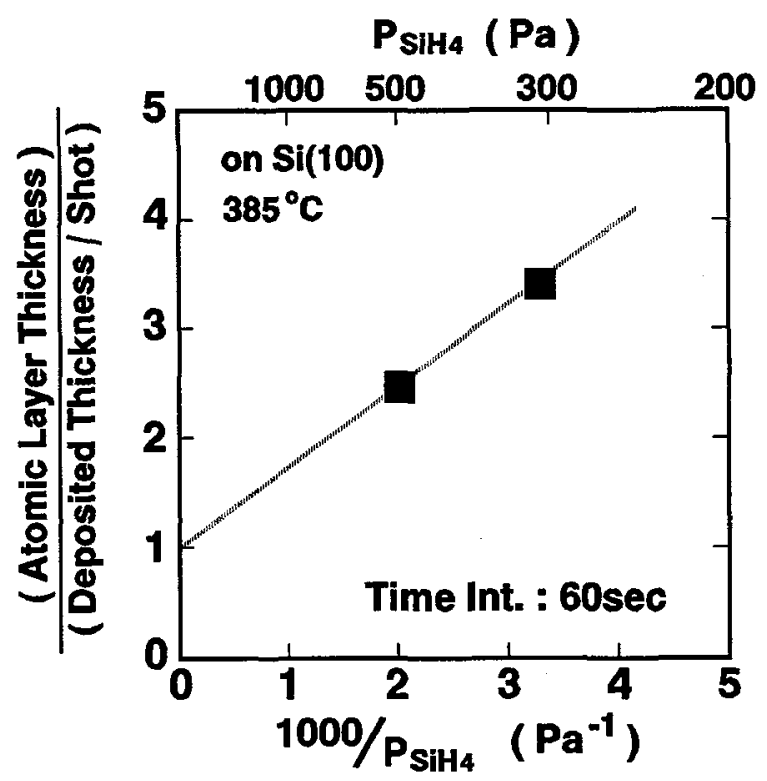

Fig.5.-The $\left(\mathrm{P}_{\mathrm{SiH} 4}\right)^{-1}$ dependence of the inverse of deposited thickness per flash light shot in the saturation region. The shot to shot time interval is $60 \mathrm{sec}$. 
the equation (4) using the following parameters, $\mathrm{d}_{\mathrm{AL}}=1.36 \AA, \mathrm{k}_{1}=7.0 \times 10^{-5} \mathrm{~Pa}^{-1} \mathrm{sec}^{-1}$, $\mathrm{k}_{-1}=5.2 \times 10^{-2} \mathrm{sec}^{-1}$ on $\mathrm{Si}(100)$ with $\mathrm{n}_{0}=\mathrm{N}$. The calculated curves are in good agreement with the experimental data. Consequently, the adsorption process of $\mathrm{SiH}_{4} \mathrm{can}$ be explained quantitatively by Langmuir-type adsorption model, assuming that the total adsorption site density is equal to the surface atom density.

Figure 6(a) shows the typical RHEED pattern taken from the film deposited on $\mathrm{Si}(100)$ surface by flash heating at the substrate temperature of $385^{\circ} \mathrm{C}$ using $\mathrm{SiH}_{4}$ gas. All the films deposited at $385^{\circ} \mathrm{C}$ were epitaxial and smooth as determined by similar streak pattern to the above. The RHEED pattern of Figure 6(a) has weak 2-fold streaks beside bright fundamental $1 \times 1$-streaks, although only bright fundamental $1 \times 1$-streaks are observed on $\operatorname{Si}(100)$ surface after the wet cleaning as shown in Figure 6(b). A similar RHEED pattern to Figure 6(a) was also obtained when the film was deposited by flash heating CVD after the double-domain $2 \times 1$ reconstructed surface (Figure $6(\mathrm{c})$ ) was formed by continuous thermal decomposition of $\mathrm{SiH}_{4}$ at $580^{\circ} \mathrm{C}$. In other words, the $2 \times 1$ reconstructed surface is mostly transformed into the $1 \times 1$ non-reconstructed surface by flash heating CVD under the conditions of high $\mathrm{SiH}_{4}$ partial pressure and of low-temperature

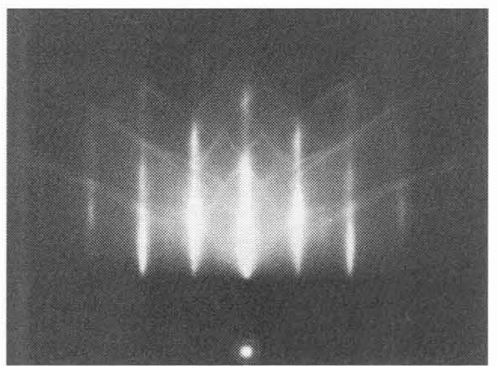

(a)

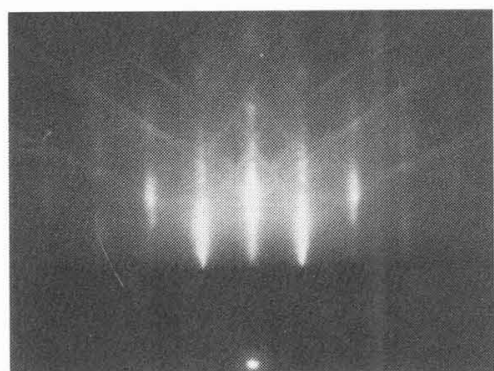

(b)

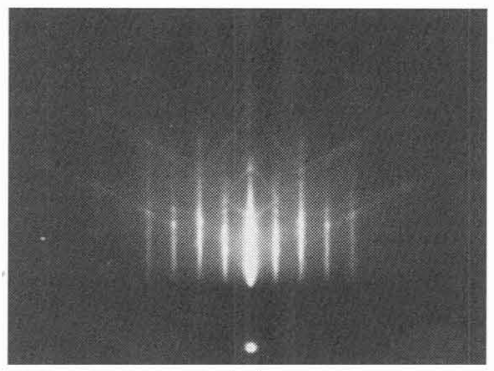

(c)

Fig.6.-Typical RHEED patterns taken from [011] azimuth for (a) the Si film deposited with 500 shots, the shot to shot time interval $24 \mathrm{sec}$, at the substrate temperature $385^{\circ} \mathrm{C}$ and the $\mathrm{SiH}_{4}$ partial pressure $300 \mathrm{~Pa}$, (b) non-reconstructed $\mathrm{Si}(100)-1 \times 1$ surface after wet cleaning as stated in Experimental and (c) reconstructed $\mathrm{Si}(100)-2 \times 1$ surface formed by continuous thermal decomposition of $\mathrm{SiH}_{4}$ at $580^{\circ} \mathrm{C}$. 


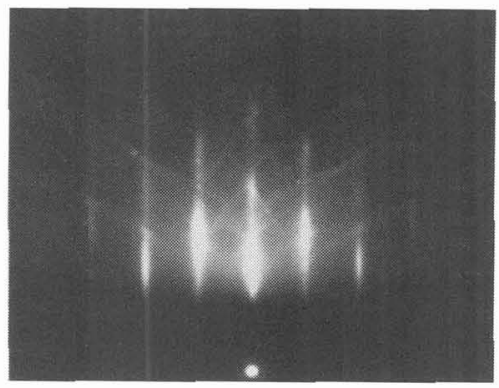

Fig.7.-Typical RHEED pattern for the Si film deposited at the substrate temperature of $320^{\circ} \mathrm{C}$ on $\mathrm{Si}(100)$ surface with 500 shots, the shot to shot time interval 20sec, the $\mathrm{Si}_{2} \mathrm{H}_{6}$ partial pressure $300 \mathrm{~Pa}$.

below $400^{\circ} \mathrm{C}$. Therefore, it is suggested that, at a high $\mathrm{SiH}_{4}$ partial pressure, the adsorption of $\mathrm{Si}$-hydrides suppresses the surface atom reconstruction.

In the case of $\mathrm{Si}_{2} \mathrm{H}_{6}$ gas in Figure 3, the $\mathrm{Si}$ deposition can be observed in the substrate temperatures above $320^{\circ} \mathrm{C}$. Above $330^{\circ} \mathrm{C}$, the deposited thickness per shot of flash light increases with the substrate temperature. As shown in Figure 3, the substrate temperature dependence of deposited thickness per shot of flash light has an energy of about $1.6 \mathrm{eV}$, which is equal to the activation energy of deposition rate in thermal CVD[10-11]. Therefore, it is considered that the continuous thermal decomposition of $\mathrm{Si}_{2} \mathrm{H}_{6}$ during the time interval between flash light shots, is dominant. However, at the substrate temperature range of $320-330^{\circ} \mathrm{C}$, the deposited thickness per shot of flash light scarcely depends on the substrate temperature. The deposited thickness per shot of flash light at the $\mathrm{Si}_{2} \mathrm{H}_{6}$ partial pressure of $300 \mathrm{~Pa}$ is found to be about $0.16 \AA$ and $0.23 \AA$ under the shot to shot time interval of $20 \mathrm{sec}$ and $40 \mathrm{sec}$, respectively.

Figure 7 shows the typical RHEED pattern from the films deposited on $\mathrm{Si}(100)$ surfaces by flash heating at the substrate temperature of $320^{\circ} \mathrm{C}$ using $\mathrm{Si}_{2} \mathrm{H}_{6}$ gas. This $1 \times 1$-streak pattern is the same as the pattern observed from $\mathrm{Si}(100)$ surface as shown in Figure 6(b). Therefore, it is considered that the initial flat surface was maintained during flash heating $\mathrm{CVD}$ at $320^{\circ} \mathrm{C}$.

\section{4.-Conclusions.}

$\mathrm{Si}$ atomic layer growth processes on $\mathrm{Si}$ substrates were investigated by flash heating CVD. The deposited thickness per shot of flash light is independent of the substrate temperatures in the ranges of $385-395^{\circ} \mathrm{C}$ for $\mathrm{SiH}_{4}$ and $320-330^{\circ} \mathrm{C}$ for $\mathrm{Si}_{2} \mathrm{H}_{6}$. In the case of $\mathrm{SiH}_{4}$, the deposited thickness per shot of flash light increased and saturated with the time interval and the saturated thicknesses on $\mathrm{Si}(100)$ were about $0.12 \AA, 0.40 \AA$ and $0.55 \AA$ for $100 \mathrm{~Pa}, 300 \mathrm{~Pa}$ and $500 \mathrm{~Pa}$, respectively. The adsorption process of $\mathrm{SiH}_{4}$ can be explained quantitatively by Langmuir-type adsorption model, assuming that the total adsorption site density is equal to the surface atom density. In the case of $\mathrm{Si}_{2} \mathrm{H}_{6}$, sub- 
monolayer growth of $\mathrm{Si}$ was observed at the substrate temperature of $320^{\circ} \mathrm{C}$ under $\mathrm{Si}_{2} \mathrm{H}_{6}$ partial pressure of $300 \mathrm{~Pa}$. But, for the $\mathrm{Si}_{2} \mathrm{H}_{6}$ surface adsorption process, further investigations will be necessary. From the RHEED observation, it is confirmed that, by using flash heating $\mathrm{CVD}$, epitaxial growth of $\mathrm{Si}$ films on $\mathrm{Si}(100)$ was realized at temperatures such as $385^{\circ} \mathrm{C}$ and $320^{\circ} \mathrm{C}$ by using $\mathrm{SiH}_{4}$ and $\mathrm{Si}_{2} \mathrm{H}_{6}$, respectively, and the surface flatness of the deposited films was as good as that of the initial surface. Furthermore, from the transformation of the streaks in the RHEED pattern, it is suggested that the adsorption of $\mathrm{Si}$-hydrides suppresses the surface atom reconstruction.

\section{Acknowledgments.}

The authors wish to express their thanks to Profs. Yasuji Sawada and Takashi Matsuura for their advice and encouragement in executing this study. The CVD reactor was provided by Kokusai Electric Co., Ltd. The study was carried out in the Superclean Room of the Laboratory for Microelectronics, Research Institute of Electrical Communication, Tohoku University, and was partially supported by a Grant-in-Aid for Scientific Research from the Ministry of Education, Science, and Culture of Japan.

\section{References.}

[1] Suntola T., Antson J., Pakkala A. and Lindfors S., Soc. Information Display (SID'80) Digest (1980) 109.

[2] Nishizawa J., Abe H. and Kurabayashi T., J. Electrochem. Soc. 132 (1985) 1197.

[3] Takahashi Y., Ishii H. and Fujinaga K., ibid. 136 (1989) 1826.

[4] Takahashi Y. and Urisu T., Extended Abstracts 22nd (1990 Intern.) Conf. on Solid State Devices and Materials, Sendai (1990) 917.

[5] Gates S. M., Surface Sci. 195 (1988) 307.

[6] Sakuraba M., Murota J., Mikoshiba N. and Ono S., J. Crystal Growth 115 (1991) 79.

[7] Murota J., Sakuraba M., Mikoshiba N. and Ono S., J. Phys. IV France 1 (1991) C2803.

[8] Sakuraba M., Murota J., Mikoshiba N. and Ono S., Extended Abstracts 23rd (1991 Intern.) Conf. on Solid State Devices and Materials, Yokohama (1991) 147.

[9] Murota J., Furuno M., Kato M., Mikoshiba N., Ono S., Kurokawa H., Sato T., Nakamura N. and Ikeda F., The Electrochem. Soc. Extended Abstracts, Fall Meeting, Seattle, WA (1990) 576.

[10] Mishima Y., Hirose M., Osaka Y., Nagamine S, Ashida Y., Kitagawa N. and Isogaya K., Jpn. J. Appl. Phys. 22 (1984) L46.

[11] Nakayama S., Yonezawa H. and Murota J., Jpn. J. Appl. Phys. 23 (1984) L493. 